\title{
Physical Concept of Shear Fracture Mesomechanism and its Applications
}

Vision article

\author{
Edward S. Dzidowski*
}

Wroclaw University of Technology, Faculty of Mechanical Engineering, 25 Smoluchowskiego Str., PL 50-372, Wroclaw, Poland

Received 08 February 2011 ; accepted 26 May 2011

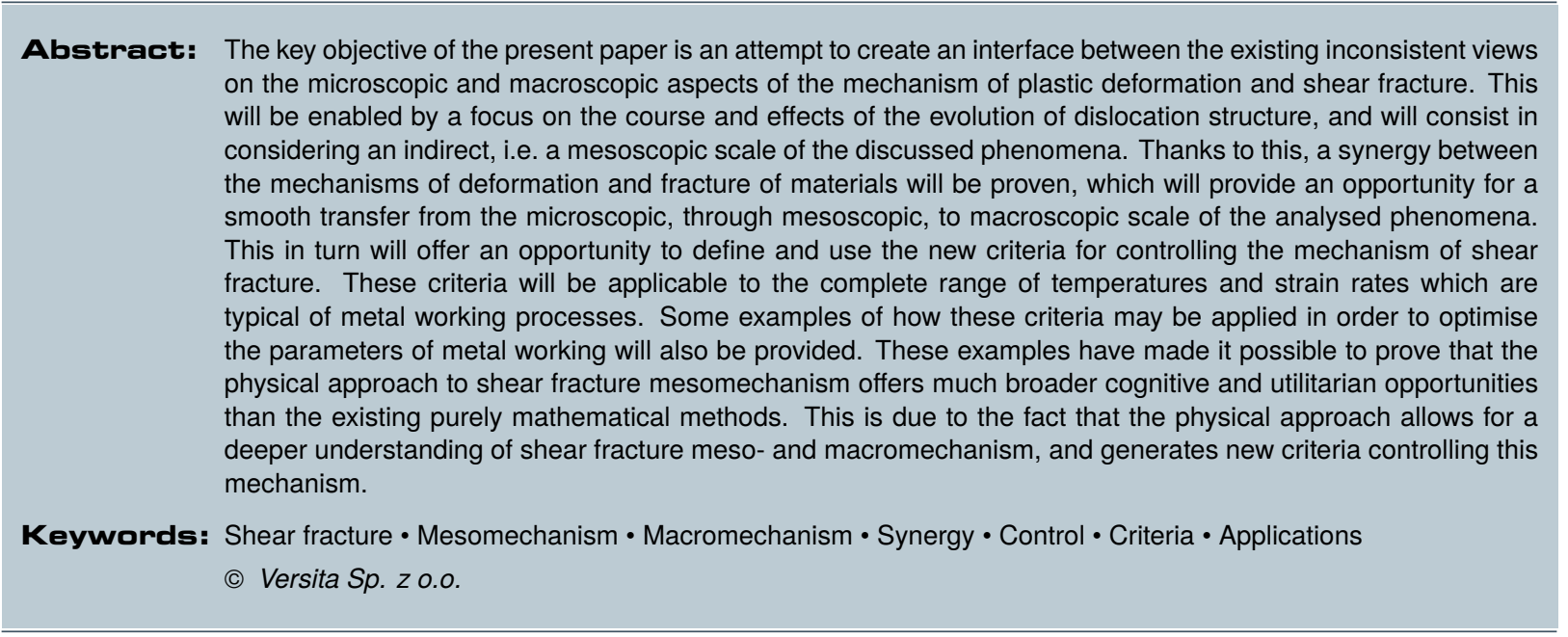

\section{Introduction}

The fracture of materials is a primary restriction for the effective use of metal working processes. The above problem is intensified by the lack of a coherent theory of deformation and fracture resulting from large plastic deformation. This state of affairs impedes the analysis of cause and effect relationships and consequently affects the prediction, prevention and/or control of the course of fracture

*E-mail: edward.dzidowski@pwr.wroc.pl of materials during metal working processes. The most acute problem is lack of capacity to control the course of fracture which in many cases involves no danger but is essential to metal working processes including shearing off, die shearing, or machining.

Therefore, the key objective of the present paper is an attempt to create an interface between the existing inconsistent views on the microscopic and macroscopic aspects of the mechanism of plastic deformation and shear fracture. This will be enabled by a focus on the course and effects of the evolution of dislocation structure, and will consist in considering an indirect, i.e. a mesoscopic scale of the discussed phenomena. Thanks to this, a synergy between 
the mechanisms of deformation and fracture of materials will be proven, which will provide an opportunity for a smooth transfer from the microscopic, through mesoscopic, to macroscopic scale of the analysed phenomena. This in turn will offer an opportunity to define and use the new criteria for controlling the mechanism of shear fracture. These criteria will be applicable to the complete range of temperatures and strain rates which are typical of metal working processes. Some examples of how these criteria may be applied in order to optimise the parameters of cold and hot metal working will also be provided.

Moreover, the usefulness of mesoscopic fracture concept will be presented with a view to revise the existing opinions on the forming limit diagram for sheet metal forming processes, as well as the views on the mechanisms of the formation of various chip types in the course of machining. Another example of the application of those criteria will be to prove the usefulness of mesomechanics for the interpretation of the reasons for the degradation of the properties of materials which are to be used in increased temperatures. The issue discussed here is the degradation of useful properties resulting from cold metal working. To provide an example, the above refers to the pipe bending process applied in the construction of pipelines in heat and power generating plants, and other similar facilities. The perspective of further development and wider usage of the mesoscopic concept of failure and fracture of materials accompanying large plastic deformation will also be indicated.

\section{Hitherto existing views on the mechanisms of fracture of materials}

\subsection{Macroscopic views on the mechanism of shear fracture}

The earlier macroscopic methods of the analysis of the development of strains and fracture in processes based on shear were based mainly on the slip line field theory and the theory of transition zones. Both theories have serious limitations. According to the slip line field theory (Fig. 1a), the plastic sinking of the cutting tool in the sheared material first causes gradual widening and then narrowing of the plastic strain area [1]. Characteristically, this area finally assumes the shape and dimensions of a line (a plane) with zero thickness (Fig. 1a, IV). The line defines the location of slip velocity discontinuity and it is identified with the presumed trajectory of fracture. It is thought that the only way in which the shape of the fracture trajectory can be changed is by eliminating the rotation (bending) of the sheared material, which is usu-

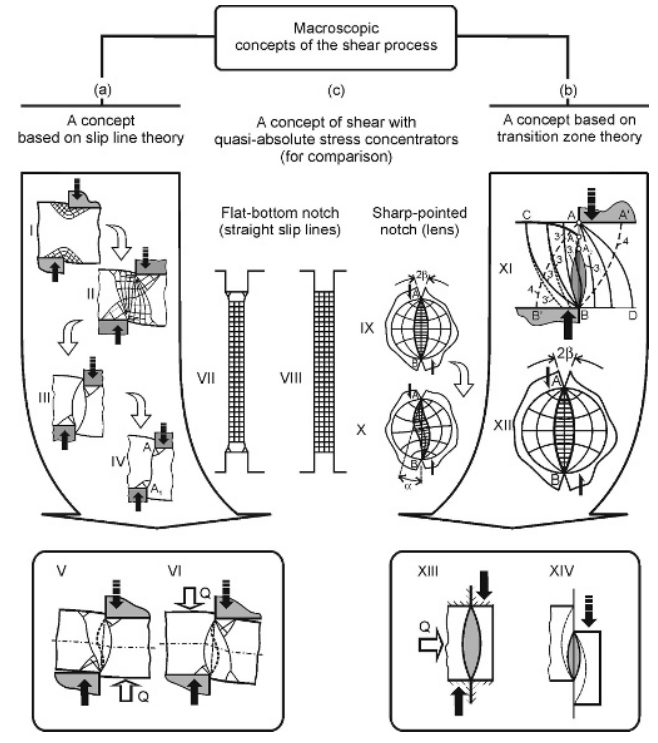

Figure 1. Macroscopic concepts of shear process: a) shear stages according to slip line theory (IIIV) and effect of clamp Q on shape of slip velocity discontinuity line as likely fracture trajectory $(\mathrm{V}-\mathrm{VI})$; b) shear stages according to transition zone theory (XI-XIV); c) distribution of slip lines for shear with flat (VII-VIII) and sharp-pointed (IX-X) stress concentrator. Based on [1] and [2].

ally done by pressing the sheared material against the cutting tool (Fig. 1a, V-VI). With this the possibilities of the method are exhausted. The fact that shear strain determined by this method approaches infinity poses an additional problem. The problem has been partially solved by the development of the theory of transitional zones.

The introduction of the theory of transitional zones (Fig. 1b) made the values and distribution of strain in the final stage of shearing real [2]. This means that instead of a line (a surface) with zero thickness (Fig 1a, IV), an area having the shape of a biconvex lens is considered (Fig. 1b, XI-XII). The beginning of the formation of this area is identified with conditions corresponding to the action of an absolute stress concentrator (Fig. 1c, VII-X). But it is not known when and why such a significant change in the stress concentration conditions occurs. Moreover, it is assumed that once the lens is formed, it does not change its shape but only diminishes as the displacement of the cutting tool increases (Fig. 1c, XIII-XIV).

To sum up, the above macroscopic theories do not explain clearly enough the mechanism and causes of the fracture of a material during its shearing. This makes the control and optimisation of shear-based processes (machining, die shearing, etc.) difficult. 


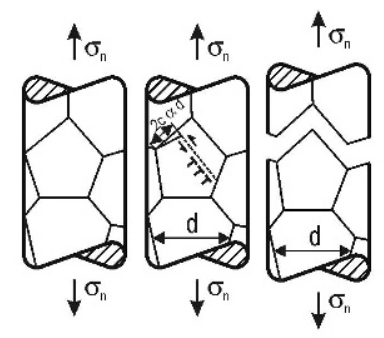

(a)

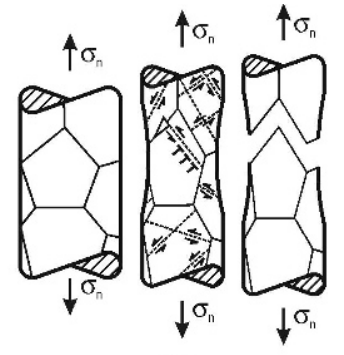

(b)

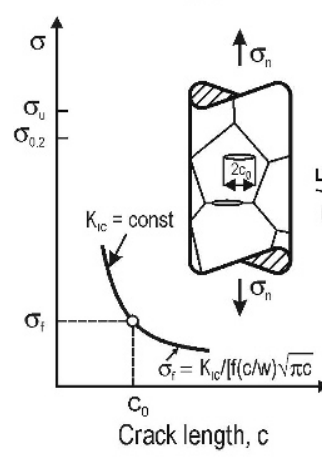

(c)

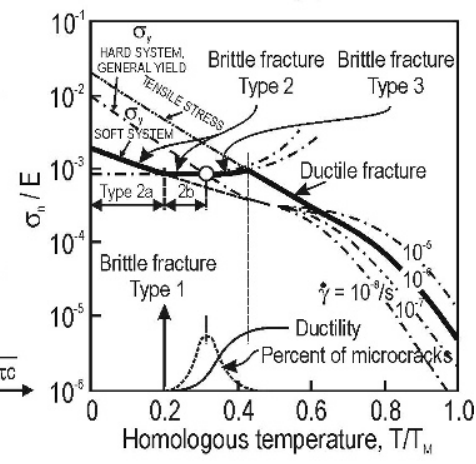

(d)

Figure 2. Mechanisms of brittle fracture: a) type 2, b) type 3, c) type $1, \mathrm{~d})$ definition of the three type of brittle fracture. Based on [3-6].

\subsection{Microscopic views on the mechanism of fracture}

Typical views on fracture mechanisms are presented on maps of fracture mechanisms (Figs. 2 and 3).

As the figures show, the brittle fracture mechanisms (Fig. 2a, b) and the ductile fracture ones are explained quite differently even though both require preceding plastic deformation. The brittle fracture mechanism is explained by the effects of a flat pile-up of dislocations (Fig. 2a,b), whereas the ductile fracture mechanism (Fig. 3a) is explained by the nucleation and development of voids around inclusions and separations. This means that two different theories of fracture are applied here: the theory of dislocations in the case of brittle fracture and a modified theory of the porous body in the case of ductile fracture [3-6].

Problem. Due to the lack of cohesion between the above theories the causes of the transition from ductility to brittleness (Fig. 2d) cannot be clearly explained. Moreover, the above model of the ductile fracture mechanism does not explain the fracture of pure metals or the fracture of monophase metal alloys. Neither does this model generate any criteria for the control of the trajectory of shear fracture. Since it is not possible to control the trajectory of shear fracture, several technical problems, connected with,

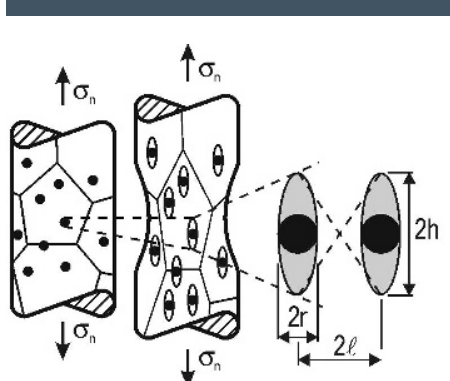

(a)

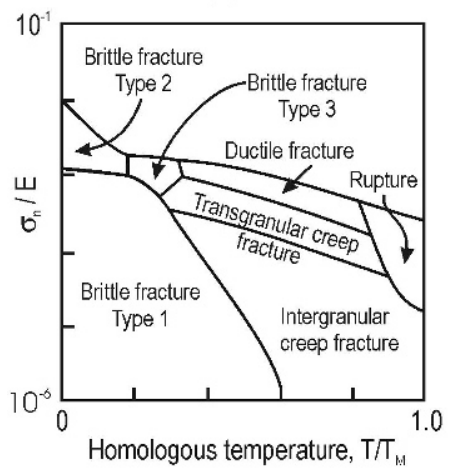

(c)

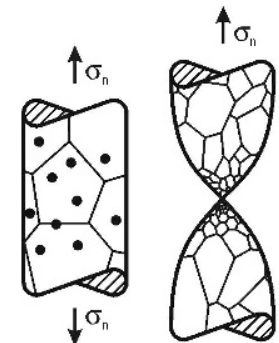

(b) $\downarrow \sigma_{\mathrm{n}}$

$\uparrow \sigma_{\mathrm{n}}$

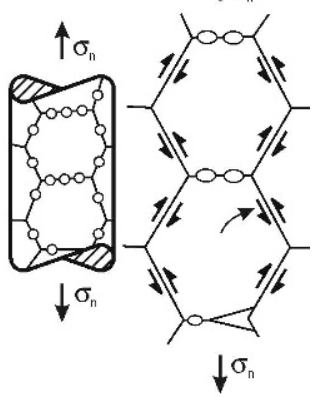

(d)
Figure 3. Mechanisms of non-brittle fracture: a) ductile, b) rupture, c) fracture mechanism map, d) intergranular creep fracture. Based on [3-6].

e.g., the precision of die shearing and similar technological processes, arise. Neither is the problem of shear fracture trajectory control solved by the theory of adiabatic shear bands (Fig. 4).

\subsection{Maps of deformation mechanisms}

Figure 4 shows the location of the areas in which adiabatic shear bands occur depending on the kind of material, the rate of its deformation, the temperature and the magnitude of the strains (not shown on the map) grey area in Fig. 4. According to Fig. 4, adiabatic shear bands (ASB) occur during cold deformation. The presence of adiabatic shear bands is equated with thermal softening which takes place in the region of the dislocation mechanism of deformation (blackened area on Fig. 4). Adiabatic shear bands appear only after critical strain $\gamma_{\text {crit }}$ and critical strain rate $\gamma_{c r i t}^{*}$ are exceeded. Moreover, their appearance largely depends on temperature. In some cases, the temperature is very low, e.g. for aluminium it is about about 200 degrees centigrade below zero.

Problem. The theory of adiabatic shear bands does not explain the mechanism of shear fracture which occurs at strain rates lower than the critical ones $\left(\nu_{\text {crit }} \mathrm{i} \gamma_{c r i t}^{*}\right)$.

Therefore one can conclude that the shear fracture prob- 

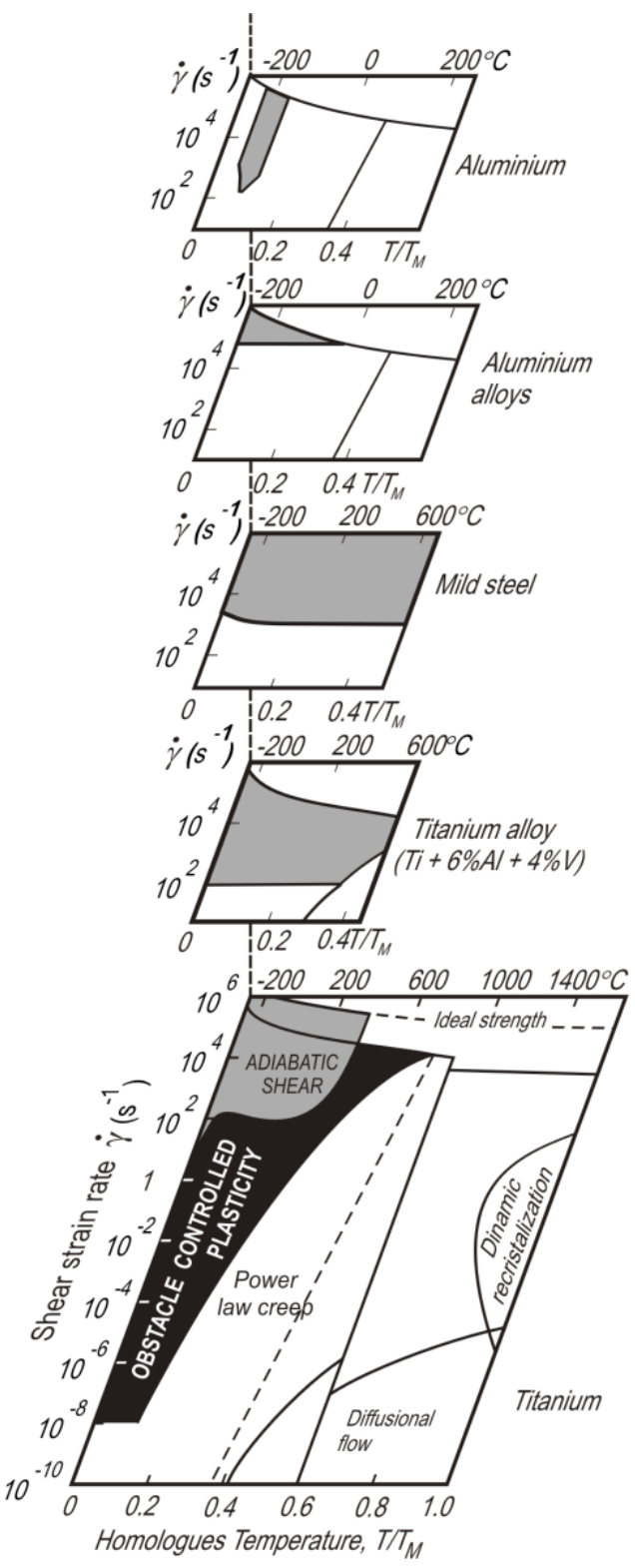

Figure 4. Strain rate/homologous temperature deformation maps. Based on $[7,8]$.

lem still is not fully correlated with the dislocation mechanism of plastic deformation, although the research on the evolution of dislocation structures seems to be quite advanced (Fig. 5).

\subsection{Maps of dislocation structures}

Figure 5 shows a map of the evolution of dislocation structures depending on temperature and the magnitude of strain. Characteristic strain values divide the map into three main areas separated from each other by thick lines. The upper limit of the first area marks the strain measured at the end of the yield threshold $\left(\epsilon_{p}\right)$. The upper limit of the second area is marked by uniform strains $\left(\epsilon_{r}\right)$. The boundaries of the third area are marked by failure strains $\left(\epsilon_{f}\right)$.

Against the background of the three areas the boundaries of subareas, corresponding to the successive stages in the evolution of the dislocation structures, can be distinguished. No complete coincidence of the boundaries of the subareas and those of the three main areas is observed, however this poses no problem for the approach adopted below. The present author proposes to focus on the subarea with strongly disoriented cellular structure (the shaded subarea in Fig. 5). In the author's opinion this subarea is closely linked to the shear fracture mechanism.

Problem. The above subarea of strongly disoriented cellular structure is not contiguous with the failure strain $\left(\epsilon_{f}\right)$ curve. In other words, there is still no clear connection between the evolution of dislocation structures and ductile fracture, and particularly shear fracture.

This is due to, among other things, the fact that a cellular structure belongs to low-energy structures, and as such does not explain the causes of the fracture.

\section{Basic problems, restrictions and paradoxes resulting from the applica- tion of the hitherto existing theories of strain localization and fracture}

\subsection{Problems of chip formation mechanism modeling}

The condition and surface properties of a machined material and the wear and life of the tools depend on the type of chip formed during machining. The type of chip also significantly affects the operation of the machine tools, especially numerically controlled ones.

Although there are only three basic types of chip (discontinuous, segmental and continuous) [10-12], no physical model exists which would explain why and how a chip of one type changes into a chip of a different type. Due to the lack of such a model, the effective control of the machining process is still unattainable. One should note that according to the current machinability criteria [13] no improvement in the machinability of monophase materials is possible.

The modelling of chip formation has been the subject of intensive researches for a long time. Although many models 


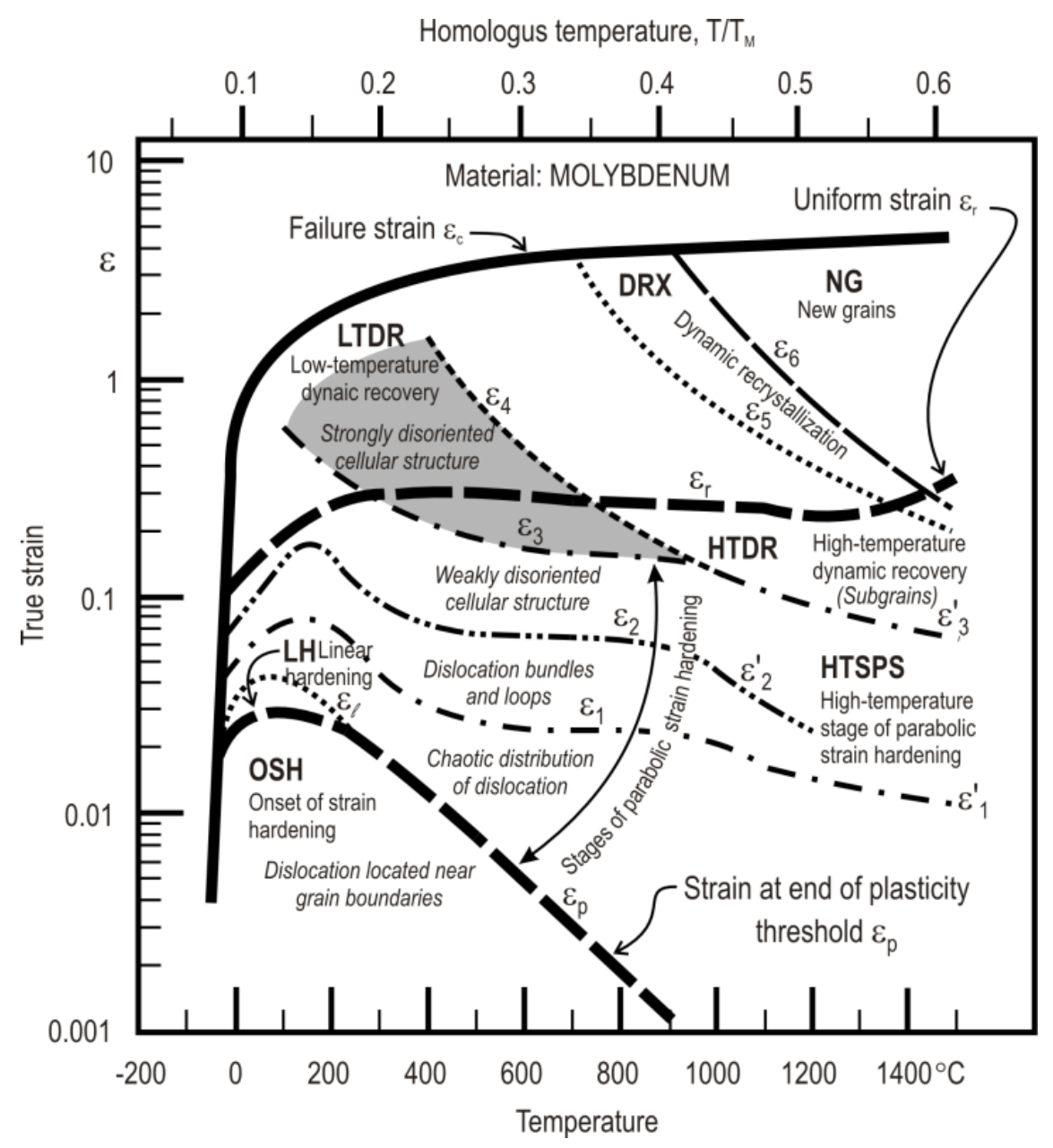

Figure 5. Map of dislocation structure evolution. Based on [9].

have been created, some of the first models, i.e. Pispanen's model (1937) and Merchant's model (1945) - Fig. 6a, are most often found in textbooks [14-16]. This is due to the fact that none of the more advanced models (Fig. 6a) [17_ 20] explains the formation of more than one type of chip and usually the stabilized stage in the formation of a homogeneous chip is modelled.

The basic reason for this state of affairs is the limitations of continuous medium mechanics due to which the commonly used models do not generate fracture criteria and thus are unable to account for the other types of chip.

The least questionable are sawtooth chip models. They are probably the only models which are physically and theoretically well-grounded, since this type of chip can be easily linked to the presence of adiabatic shear bands (Fig. 6b) [21-24]. This, however, does not mean that each sawtooth chip is connected with adiabatic shear [25]. Moreover the questions of how chips of the other types are formed and what should determine the boundaries of their occurrence on maps of deformation mechanisms (Fig. 6b) [26] still remain unanswered. According to Fig. 6b, the rate of deformation is not a clear-cut criterion for such demarcation, especially as the occurrence of the particular types of chip is not accompanied by a change in the plastic strain mechanism (the shaded areas in Fig. 6b).

All of this discourages a search for new physical chip formation models and purely numerical models are used instead (Fig. 6c) [27-30]. There are no indications that numerical models represent a viable alternative since they do not generate any more physics than the one already contributed by the previously made assumptions based on the current knowledge about machining.

This means that the modelling of the mechanism of chip formation and change of one type of chip into another still remain out of reach. 


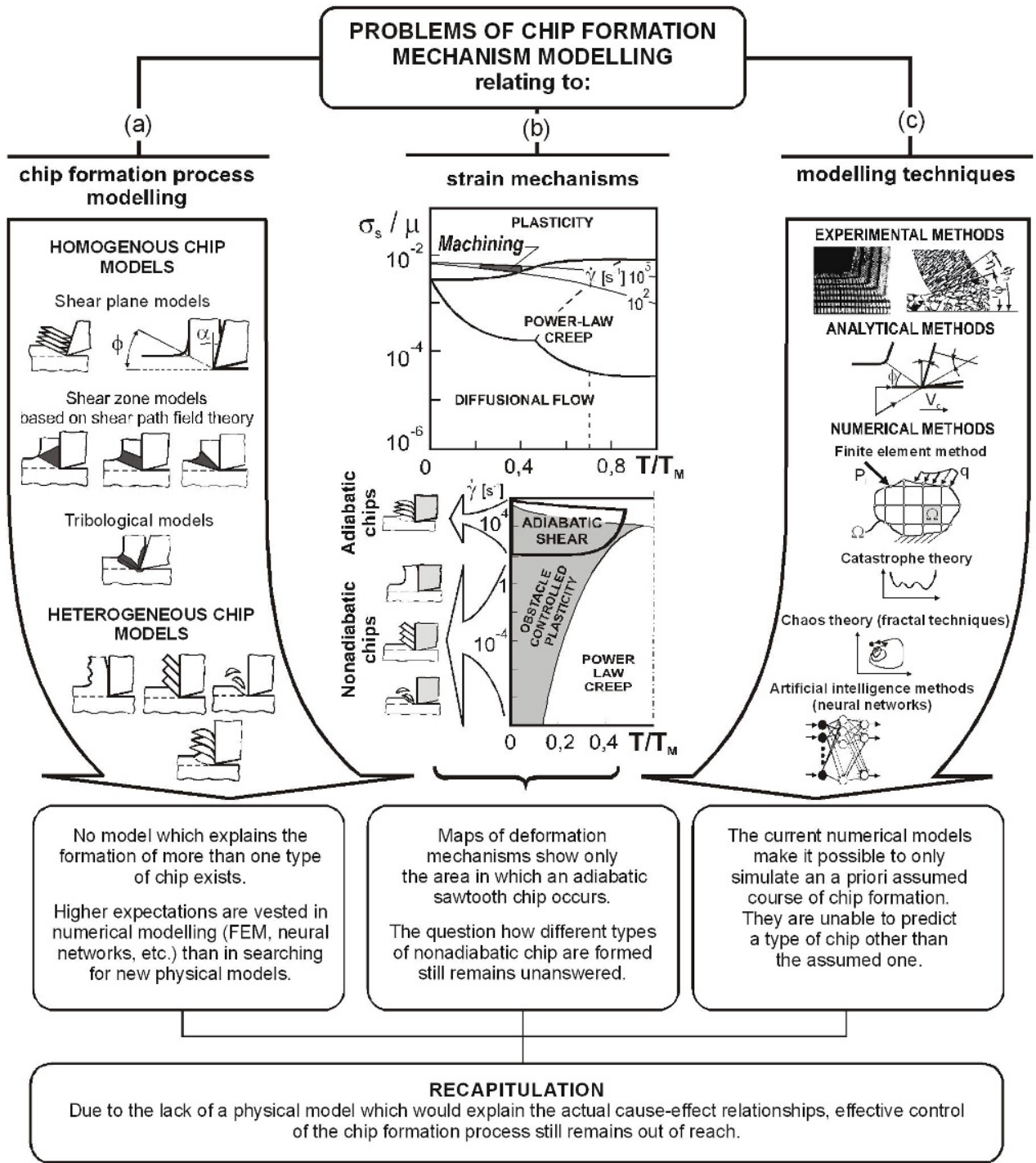

Figure 6. Synthetic illustration of problems related to chip formation mechanism modelling.

\subsection{Problems and paradoxes of the hitherto existing limit strain curve concept}

Strain localization and fracture are generally regarded to be the phenomena which ultimately delimit sheet metal forming (Fig. 7a).

Limit strain curves (LSCS) are most commonly used to determine limit strains relating to the above two limitations. Although the curves are used to determine the values of both kinds of limit strains, strain-localization LSCs are still regarded to be superior. The appearance of a furrow - strong local thinning of the formed material - is thought to be a tangible sign of strain localization. This strain localization criterion is purely geometric. Further- more, different strain localization criteria have to be used for different states of strain (the problem of LSCs' left and right side) - Fig. 7b,d. In the author's opinion, identifying strain localization exclusively with local thinning of the material ignores the physical sense of this phenomenon and blurs its close link to fracture.

The use of necking as a strain localization criterion and the treatment of sheet metal fracture as a sort of reference point for the experimental determination of LCSs (Fig. $7 \mathrm{~g}$ ) is a source of fallacious notions about the strain localization-fracture relationship (Fig. 7i).

In the author's opinion the view that in certain strain intervals fracture occurs without strain localization (Fig. 7i) is paradoxical. This view concerns the forming of sheet 
(a)

Plane state of strain

$$
\beta=0
$$

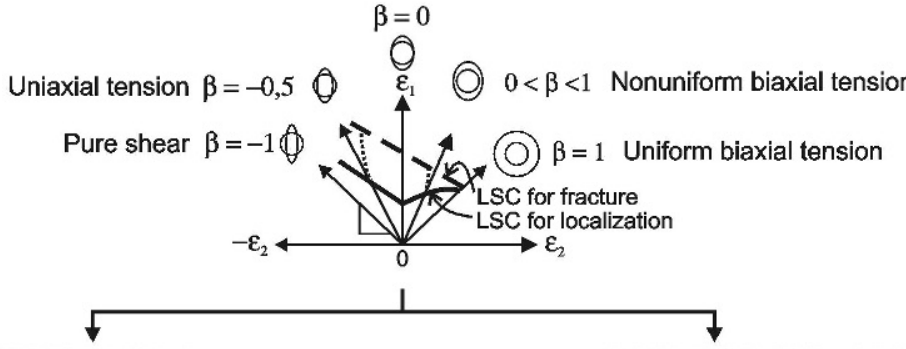

MAJOR LIMITATIONS ASSOCIATED

MAJOR LIMITATIONS ASSOCIATED

WITH STRAIN LOCALIZATION

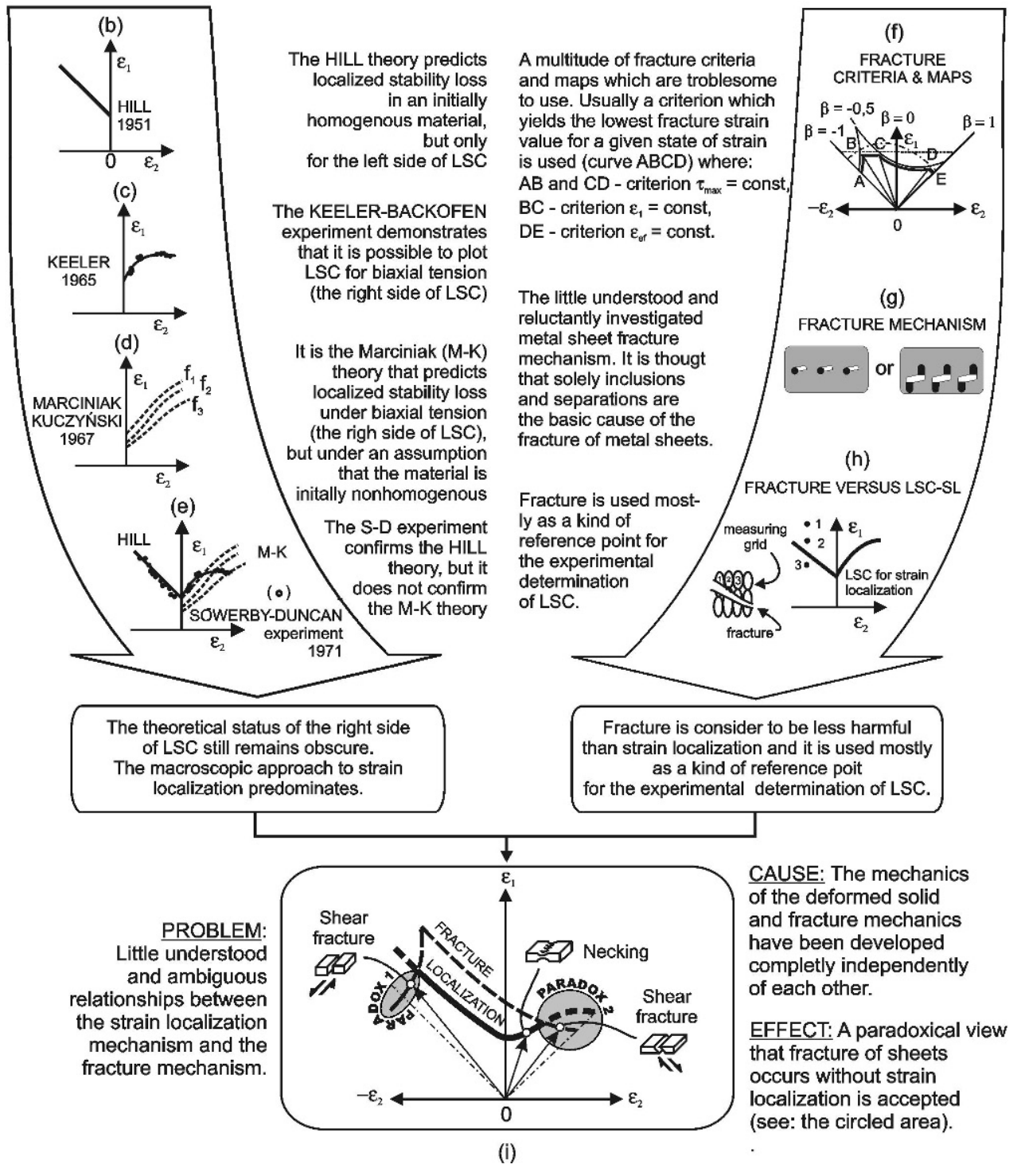

Figure 7. Synthetic illustration of problems related to limit strain curves (LSCs) construction. 
metal by close to pure (cup) drawing (the left side of LSCS - paradox 1) and forming close-to-uniform biaxial tension (the right side of LSCs - paradox 2) - Fig. 7i. This leads to false notions about the relationships between strain localization and sheet metal fracture in different states of strain, and to incorrect estimates of the limit strains.

\section{Mesoscopic-macroscopic con- cept of fracture of materials accom- panying large plastic deformation}

The mesoscopic-macroscopic concept of the shearing process, proposed by the author of this paper, is illustrated in Figs. 8 and $9[31,32]$. According to this concept, the onset (Fig. 8b) and then the development of strain localization in mesoscopic shear bands (Fig. 9a) are of key importance. Here a case of strain localization in quasi-isothermal, mesoscopic shear bands (SB) is considered. The development of shear bands manifests itself in the appearance of a lenticular strain localization zone (Fig. 8b). The beginning of strain localization in the mesoscopic shear bands puts an end to the displacements of the free surface: $U_{s}$ $=U_{s, \max }($ Fig. 8a, b). The moment when shear bands appear and the free surface displacements are inhibited can be easily predicted. It is enough to know the relationship between limiting strain $U_{l}$ and strain-hardening coefficient $n[33,34]$. Strain (displacement) $U_{l}$ is limiting from the strain localization point of view. The development and properties of the dislocation structure within shear bands (Fig. 8 h, i, j) determine the susceptibility of the material to fracturing along the shear bands. The original grain boundaries become defective as a result of the interaction between them and the shear bands (Fig. 9a, boundary GB2). This means that the course and effects of the shearing process depend here only on the synergy between the strain localization mechanism and the mechanism of fracture along mesoscopic shear bands.

The macroscopic course of fracture depends on the shape of the boundaries of the strain localization zone (Fig. 8b, 9b) and the magnitude of the displacements of the material along the defective grain boundaries (Fig. 9a).

\section{Mesoscopic-macroscopic model of shear fracture mechanism}

As Fig. 9 shows, the fracture of the sheared material consists in its separation along mesoscopic shear bands SB (Fig. 9a, separation $\Delta \mathrm{L}$ )). Initially the fracture propagates along the shear bands (Fig. 6b, trajectories A-B and E1-
D1) and it consists in the loss of cohesion between the particular layers of the material. As the fracture reaches points 2 and 3, the fracture mechanism changes. From now on the fracture propagates only along the defective grain boundaries (Fig. 9b, line 2-3 and Fig. 9a, boundary GB2).

Hence the final shape of fracture surface A-2-3-4' and that of surface A1-2-3-4 depend on the shape and width of the lenticular strain localization zone and on the magnitude of the displacements along the defective grain boundaries (Fig. 9 a, b). This means that the fracture initially propagates along the boundaries and then across the strain localization zone formed by the shear bands (Fig. 9b, c). Characteristically, the strain localization zone shrinks from top and bottom and eventually widens as a result of intercrystalline displacements of the material. Immediately before the total separation of the sheared material into two parts, the zone assumes a shape similar to parallelogram $\mathrm{BCE}_{1} \mathrm{~F}_{1}$ (Fig. 9b, blackened area). The above shear fracture mechanism model relates fracture not only to the properties (misorientation) of the material's substructure within shear bands, but also to transverse (acting transversely to the direction in which shear bands (SBs) develop) tensile stresses. Such stresses may arise naturally or be artificially generated as in shear with tension. One should note here that the effective value of artificially generated tensile stresses amounts to about 0.25 of the yield point value $\left(\sigma_{0.2}\right)$. Conventional shearing (Fig. 9) is an example of the natural generation of transverse tensile stresses. The stresses arise because of interaction between $\mathrm{SBs}$ and the original grain boundaries (see Fig. 9a, GB2). The development of shear bands results in strong flattening and rotation of the grains and in the formation of characteristic laminar lenticular strain localization zones (SLZ). This may be accompanied by the formation of wedge-shaped discontinuities along the original grain boundaries (see Fig. 9a, GB2). The tendency to form such discontinuities depends to a large degree on the condition of the original grain boundaries. One of the factors conducive to the lamination of the original grain boundaries may be adsorption of foreign atoms. The defective grain boundaries become similar to inclined planes whereby the sheared portions of material move and separate along the SBs (Fig. 9a, shear bands SB1-SB4 and the next ones). The separation is the most complete near the boundaries of SLZs, i.e. at the places where displacement (non-dilatational strain) gradients are the steepest (see Fig. 9 a and b). To sum up, the shape of shear fracture trajectories depends here on: the way in which shear bands develop, the properties of the shear bands, the condition of the original GBs and the shape of the SLZ formed by the mesoscopic SBs. This means that 


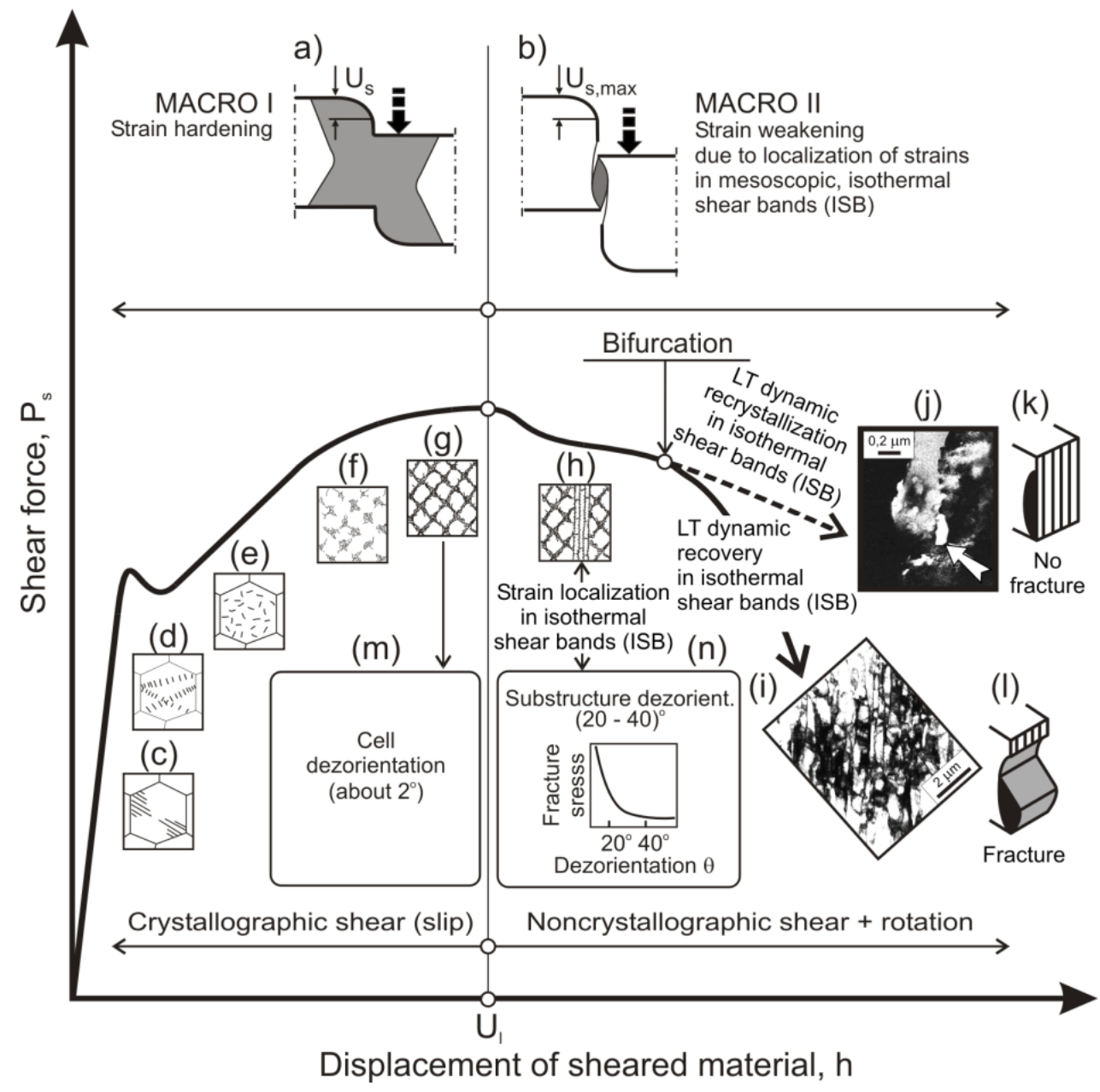

Figure 8. Mesoscopic-macroscopic concept of shearing. According to E.S. Dzidowski. Description in text.

by properly changing the properties and direction of development of shear bands and the way in which transverse tensile stresses are generated one can change the shape of the shear fracture trajectories or totally eliminate the fracture.

\section{Criteria and principles of frac- ture control resulting from the meso- scopic concept of shear fracture}

The presented mesoscopic-macroscopic concept of the physical modelling of the shearing process generates criteria for the effective control of processes based on the shearing of materials. The criteria include everything which affects strain localization in mesoscopic shear bands and the properties of the dislocation structure formed within the shear bands. Depending on the needs, stacking fault energy, the strain hardening ability of the material, the angle of disorientation of the substructure formed within the shear bands, the direction in which the shear bands propagate, the original condition of the grain boundaries, the location of the strain localization zone and so on can be such a criterion. Selected examples illustrating the possibilities of controlling the shearing process are shown in Fig. 10.

\subsection{General mesoscopic-macroscopic crite- ria and principles of fracture control in pro- cesses based on material shearing}

Figure 10 shows mainly the influence of: the length of the material's cropped part, the additional state of stress, and the properties of the shear bands on the course and 
(a)

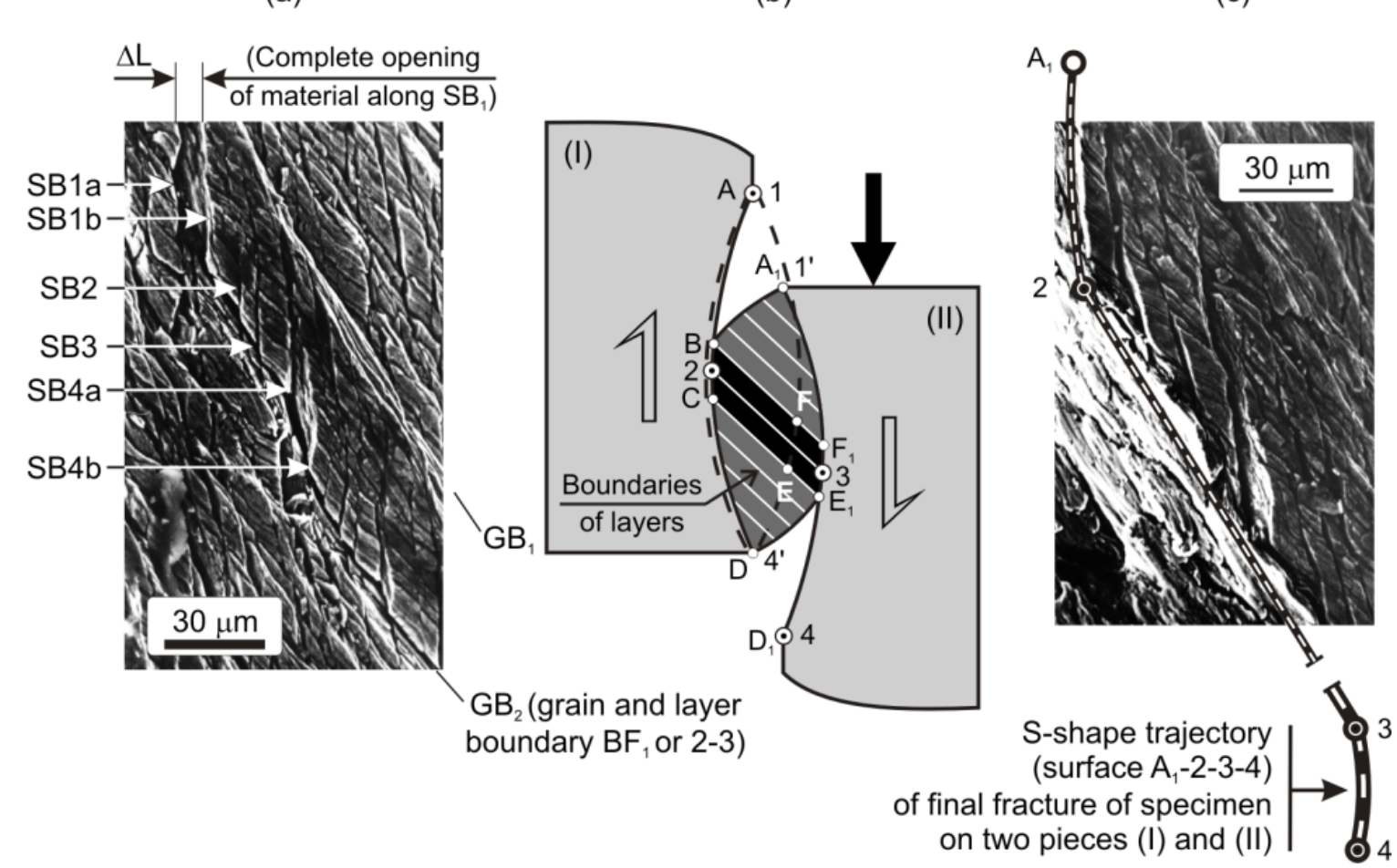

(b)

(c)

Figure 9. Model of shear fracture mechanism (b) and scanning electron microscopy results which validate it (a, c). According to E.S. Dzidowski. Description in text.

effects of shear fracture. According to figure 10, a change in the length of the cropped part leads to a change in the kind of process. In the considered case, the processes are cropping and orthogonal cutting (machining). They differ only in the shape of the macroscopic strain localization zone (MSLZ) and the way in which the latter develops. In the case of cropping, the zone assumes the shape of a biconvex lens whose axis is parallel to the direction of shearing. In the case of machining, the MSLZ assumes the shape of a half-lens whose axis is skew to the direction of shearing. Because of the skewness of the axis machining is a process of cyclic formation of countless MSLZs, owing to which a chip forms.

The type of chip depends solely on the properties of the substructure forming within mesoscopic shear bands. This means that:

- the same phenomenon, the localization of strains in mesoscopic shear bands, underlies both processes;

- the direction of development and shape of the fracture trajectory depend on the shape of the MSLZ and the way in which the transverse tensile stresses are generated;

- the material's tendency to shear fracture depends solely on the properties of the substructure which forms within shear bands.

Further to the above, the issue arises on how the properties of the substructure may be changed within the mesoscopic shear bands.

\subsection{Stacking fault energy as a criterion for controlling the mesoscopic-macroscopic mechanism of formation of various chip types}

In the mesoscopic-macroscopic concept of shear fracture mechanism presented above, the chip type depends on the tendency of the material to fracture along the boundary of the macroscopic zone of strain localisation. At the same time, the tendency for shear fracture is itself dependent on the course and effects of the evolution of dislocation structures. One may conclude that the method to change the chip type may consist in changing the stacking fault energy. This is due to the fact that the course of the evolution of dislocation structures depends on the stacking fault energy, which is shown in figure 11 . The research conducted by the author of the aforementioned paper in collaboration with his co-worker indeed confirmed such 


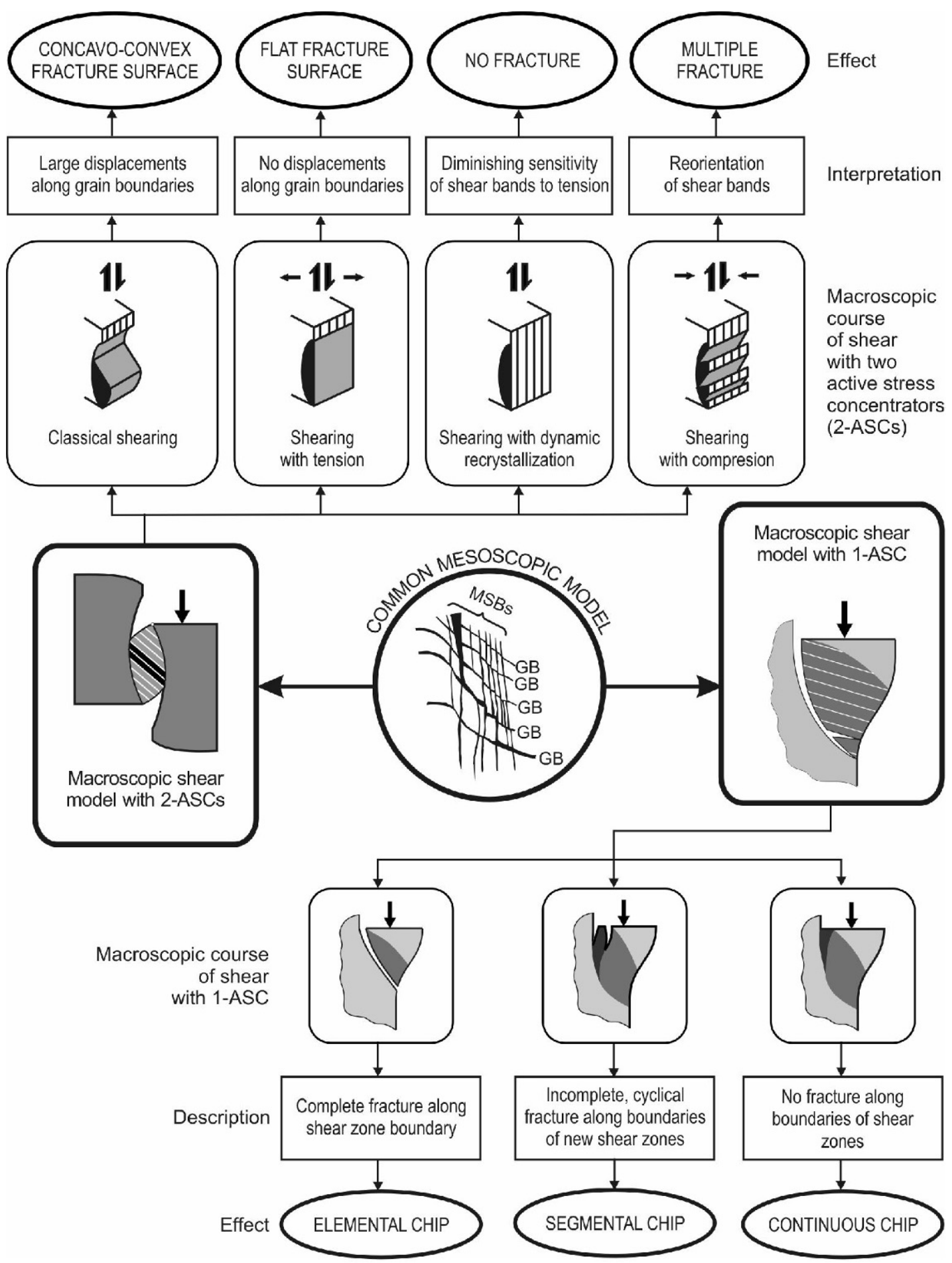

Figure 10. Examples of interpretation possibilities of mesoscopic-macroscopic model of shear mechanism (according to E. S. Dzidowski). 
$\mathrm{Cu} \quad \mathrm{Al}$

alloys alloys

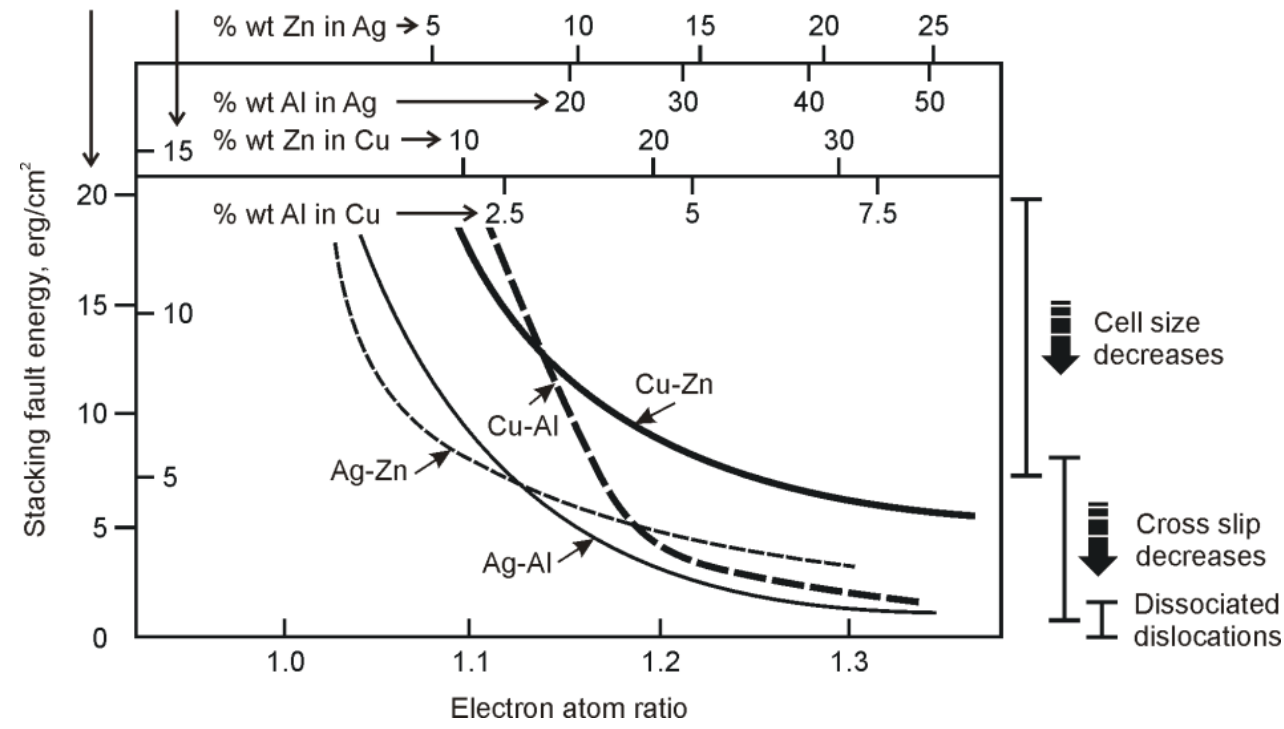

Figure 11. Dependence of dislocation cell size and tendency for cross-slip and dissociation of dislocations on stacking fault energy in copper and silver alloys. Based on Swann 1963.

a)

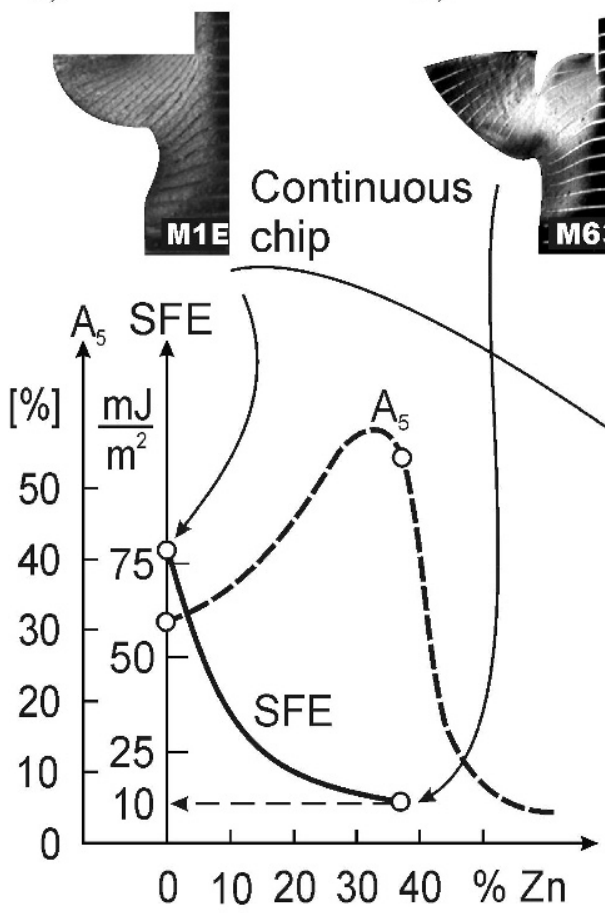

d) b)

Segmental M63 chip

c)

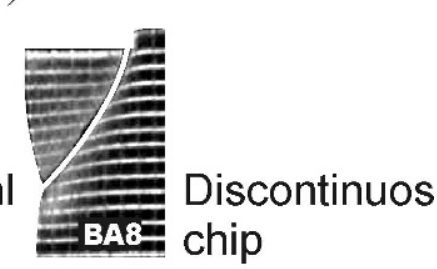


possibility, which is illustrated in the figure below [33]. As figure 12 shows, reducing the stacking fault energy (SFE) leads to a change in the type of chip from continuous (Fig. 12a) to segmental (Fig. 12b) and discontinuous chip (Fig. 12c). It should be noted that the chips formed during intense shear fracture (segmental and discontinuous chips) have been obtained in the materials more plastic $(\mathrm{Cu}+37.4 \% \mathrm{Zn})$, or as plastic as $(\mathrm{Cu}+7.2 \% \mathrm{Al})$ plain copper (see figure 12: values $A_{5}$ and $A_{10}$ ). This means that the equals sign currently put between the discontinuous chip and the brittleness of the machined material, or the presence of brittle particles [13], shall be deemed as dramatically inefficient or even incorrect, as brittle fracture has been confirmed in none of the examined materials (Fig. 12). This also means that the stacking fault energy may become a new and effective criterion for controlling the mesoscopic mechanism of chip formation during the machining, as well as for other similar processes, including abrasive wear.

\subsection{The way of developing shear bands as a criterion for the modification of the existing shape of the diagram of metal sheet limit defor- mation}

Identifying strain localization exclusively with local thinning of the material ignores the physical sense of this phenomenon and blurs its close link to fracture. This leads to false notions about the relationships between strain localization and sheet metal fracture in different states of strain and to incorrect estimates of the limit strains (Fig. 7i). The author's analysis of the problem and the results of his investigations into the strain localization mechanism and the fracture mechanism under large plastic strains have led him to the following conclusions:

1. It is possible to apply one criterion valid for the whole range of strain. This criterion should define only the conditions for the onset of strain localization understood as an intramaterial phenomenon.

2. Shear fracture of cold-formed sheet metal cannot occur without prior strain localization.

3. The critical strain value for fracture is always higher than the one for the onset of strain localization and the difference between them depends on the mode in which strain localization develops. The above theses were incorporated into a new conception of the limit strain curve (Fig. 13).

This conception is based on the assumption that the strain localization and fracture mechanisms in sheet metal have a common origin and there is a synergy between them. In fact, according to the proposed conception, there is only one strain localization mechanism: strain localiza- tion in shear bands. The way in which shear bands develop determines only the macroscopic course of strain localization and the prior-to-fracture strain values. The maximum shear stress criterion, which defines the shape of the strain-localization limit strain curve (SLLSC), was adopted as the strain localization onset criterion. The fracture limit strain curve (FLSC) is situated above SLLSC for the whole range of stress. The distance between the two curves depends mainly on the way in which strain localization develops, i.e. on the concentrated or dispersed development of shear bands. The fracture mechanism is closely bound up with the development of shear bands. The mode of fracture is determined by the local state of stress and as a result, by the state of strain (Fig. 14).

Experiments were carried out [34] to validate the assumptions of the above LSC conception, to determine the mechanism and mode of strain localization development depending on the state of strain and to establish the relationship between the investigated phenomena and limit strain values. Scanning microscopy was employed. The mechanisms and modes of the development of the phenomena were determined by examining the development of shear bands and by fractography.

The results of the investigations challenge the universality and meaning of the "furrow" strain localization criterion. It has been found that an occurrence of strain localization does not necessarily entail the appearance of a "furrow" or apparent disturbance of the sheet metal forming process. Shear bands can develop in both concentrated and dispersed mode. Thus the mode in which shear bands develop determines the macroscopic manifestations of strain localization and the critical strain values as regards fracture. This means that by "dispersing" the development of shear bands one can prevent the appearance of a "furrow" and to increase the fracture related critical strains. In this way the strain localization-fracture relationships for the right side of LSC have been explained and thus the dilemma arising from the inapplicability of the Hill criterion [35] and the limitations of the Marciniak-Kuczyński theory [36] for this side of LSC has been solved.

\section{The prospects for development and further application of mesome- chanics of failure and fracture of ma- terials}

The abovementioned examples of the application of the mesoscopic-macroscopic shear fracture concept and model do not fully exhaust all the possible applications of this model. This is due to the fact that this model gener- 


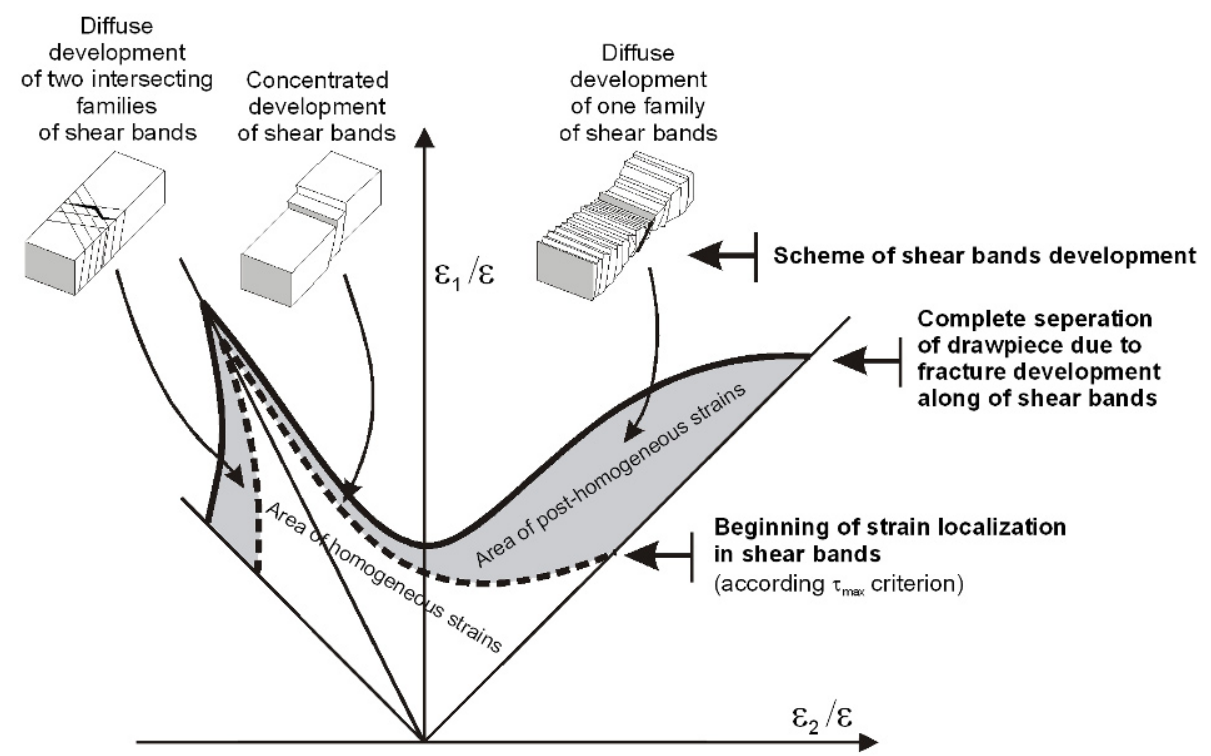

Figure 13. Proposed new, mesoscopic concept of limit diagram for metal sheet forming.

(a)

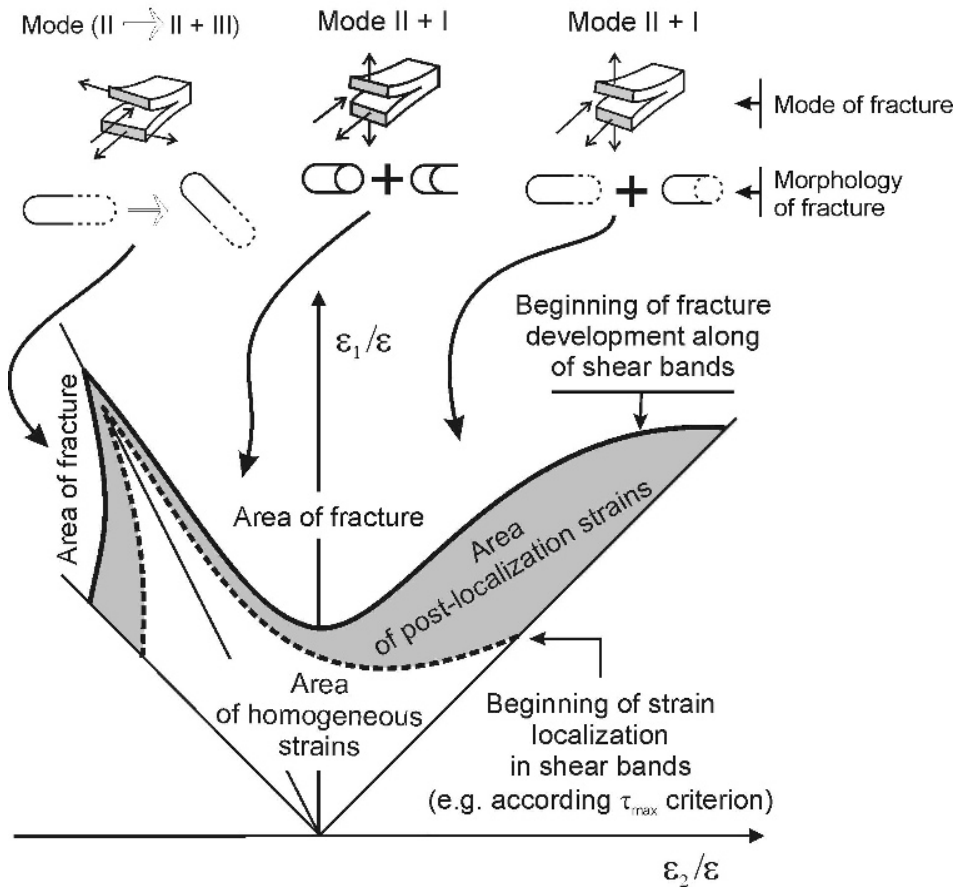

Figure 14. Effect of state of strain on mode and morphology of sheet metal fracture.

ates both the criteria for predicting the commencement of fracture, and the criteria for controlling the course of and/or the criteria for preventing shear fracture. Consequently, this model may be applied wherever large local plastic deformations occur as a result of the development of mesoscopic isothermal shear bands $[37,38]$. These examples have made it possible to prove that the physical approach to shear fracture mesomechanism offers much 
broader cognitive and utilitarian opportunities than the existing purely mathematical methods, as presented e.g. in [39-42]. This is due to the fact that the physical approach allows for a deeper understanding of shear fracture meso- and macromechanism, and generates new criteria controlling this mechanism. More details and experimental verifications of the concept presented here can be found in earlier author's publications [43-56]. For further arguments for the effectiveness of mesomechanical concept of fracture see papers [57] and [58].

\section{References}

[1] Timoshchenko V.A., Elements of theory and technology of die shearing and cropping processe, Shtiintsa, Kishinev, 1979 (in Russian)

[2] Belyaev V.I., Engineering theory of plasticity, Science and Technology, Minsk, 1985 (in Russian)

[3] Gurson A.L., Continuum theory of ductile rupture by void nucleation and growth, I. Yield criteria and flow rules for porous ductile media, J. Eng. Mater. Technol., 1977, 99, 2,15

[4] Needleman A., Tvergaard V., An analysis of ductile rupture in notched bars, J. Mech. Phys. Solids, 1984, 32, 461-490

[5] Gandhi C., Ashby M. F., Fracture-mechanism maps for materials which cleave: FCC, BCC and HPP metals and ceramics, Acta Metallurgica, 1979, 27, 15651602

[6] Ashby M. F., Gandhi C., Taplin D. M. R., Fracturemechanism maps and their construction for FCC metals and alloys, Acta Metallurgica, 1979, 27, 699-729

[7] Sarget P.M., Ashby M. F., Cambridge Univ. Engng. Dept. Report No. CUEDCMATSTR.98, 1983

[8] Bai Y., Dodd B., Adiabatic shear localization. Occurrence, theories and applications, Pergamon Press, Oxford, 1992

[9] Firstov S.A., Pechkovski E.P., Voprosy Materialobedeniya, 2002, 29, 70

[10] Komanduri R.,Brown R.H., On the Mechanics of Chip Segmentation in Machining, Journ. of Engineering for Industry, Trans. ASME, 1981, 103, 33-51

[11] Jawahir I.S.,van Luttervelt C.A., Recent Developments in Chip Control Research and Applications, Annals of CIRP, 1993, 42/2, 659-693

[12] van Luttervelt C.A., Childs T.H.C., Jawahir I.S., Klocke Fet al., Present Situation and Future Trends in Modelling of Machining Operations, Annals of CIRP, 1998, 47/2, 587-626
[13] Higgins R.A., Engineering Metallurgy. Part I Applied Physical Metallurgy, Edward Arnold, A division of Hodder and Stoughton, London, 1993

[14] Merchant M.E., Mechanics of the metal cutting process, Journal of Applied Physics, 1945, 16/5, 318-324

[15] Shaw M.C., Metal Cutting Principles, Oxford Pub., 1984

[16] Astakhov V.P., Metal Cutting Mechanics, CRP Press LLC, London, 1998

[17] Hill R., The Mathemalical Theory of Plasticity, Oxford University Press, London, 1950

[18] Hill R., The Mechanics of Machining: A New Approach, J. Mech. Phys. Solids, 1954, 3, 47

[19] Shi T., Ramalingam S., Slip-line Solution for Orthogonal Cutting with a Chip Breaker and Flank Wear, Int. J. M. Sci., 1991, 33, 9

[20] Black J.T., Briggs N.D., Huang J., Payton L.N., Orthogonal Machining of Metals, In: II International Conference on Advances in Production Engineering APE, 2001, Warsaw, 2001

[21] Recht R.F., Catastrophic Thermoplastic Shear, Journal of Applied Mechanics, 1964, 6, 189-193

[22] Recht R.F., A Dynamic Analysis of High, Speed Machining, Journal of Engineering for Industry, 1985, 107, 309-315

[23] Vyas and Shaw M.C. Mechanics of Saw-Tooth Chip Formation in Metal Cutting, Journal of Manufacturing Science and Engineering, 1999, 121, 163-172

[24] Bai Y., Dodd B., Adiabatic Shear Localization, Pergamon Press, 1992

[25] Dzidowski E.S., Chru.cielski G., Mesomechanistic Concept of Metal Cutting Processes, In: A. M. Habraken (Ed.) Proceedings of 4th International ESAFORM Conference on Material Forming, (April 23-25, 2001 Liege Belgium) Deroaux Ordina, 2001, 635-638

[26] Frost H.J., Ashby M.F., Deformation, Mechanism Maps, The Plasticity and Creep of Metals and Ceramics, Pergamon Press, Oxford, New York, Toronto, 1982

[27] Marinov V.R., Hybrid analytical-numerical solution for the shear angle in orthogonal metal cutting, Part I: theoretical foundation, International Journal of Mechanical Sciences, 2001, 43, 399-414

[28] Lin Z-C., Lin Y-Y, Fundamental Modeling for Oblique Cutting by Thermo-elastic-plastic FEM, Int. Journal of Mechanical Sciences, 1999, 41, 941-965

[29] Hamman J.C., Meslin F., Donyo S., Phenomenological Modeling of Chip Segmentation Using the Catastrophe Theory, In: The 4th International ESAFORM Conference on Material Forming, Liége, Belgium, 2001 
[30] Masory O., Monitoring Machining Processes Using Multi-sensor Readings Fused by Artificial Neural Network, J. Mat. Proc. Technol. 1991, 28 , 231-240

[31] Dzidowski E.S., Mechanism of Shear Fracture in the Aspect of Controlled Decohesion of Metals, Scientific Papers of the Technical University of Wroclaw, Monographs No. 11, Wroclaw, 1990 (in Polish)

[32] Dzidowski E.S., Microscopic-macroscopic concept of physical modelling and controlling shear fracture and processes determined by this fracture, Physical Mesomechanics, 2004, 7, 75-80

[33] Dzidowski E.S., Chruscielski G., Effect of stacking fault energy on mesoscopic-macroscopic mechanism of chip formation during shearing with single concentrator of stresses (during machining), Mechanical Review, 2005, 7-8, 31-34 (in Polish)

[34] Dzidowski E.S., Cisek W., Non-homogeneity of deformation and fracture in sheet metal forming under biaxial stretching, Archives of Metallurgy, 1999, 44, 403-419

[35] Hill R., On discontinuous plastic states, with special reference to localized necking in thin sheets, J. Mech. Phys. Solids, 1952, 1, 19-30

[36] Marciniak Z., Kuczynski K., Limit strains in the processes of stretch-forming sheet metal, Int. J. Mech. Sci., 1967, 9, 609

[37] Dzidowski E.S., How to design, manufacture and exploit pipes for secure operation under pressure, Rudy i Metale, 2008, R53, 714-721 (in Polish)

[38] Dzidowski E.S., The mesoscopic mechanism of the isothermal shear fracture of aluminium alloys. In: ed. Hirsh J., Skrotzki B., Gottstein G. (Eds.), Aluminium Alloys: their physical and mechanical properties, (2008 Weinheim), Wily-VCH, 2008, 1844-1949

[39] Wei Yang, Lee W. B., Mesoplasticity and its applications, Springer-Verlag, Berlin Heidelberg 1993

[40] Kafka V., Inelastic mesomechanics, World Scientific, Singapore 1987

[41] Kafka V., Mesomechanical constitutive modeling, World Scientific, Singapore 2001

[42] Murayama Y., Mesoscopic systems, Wiley-Vch, Weinheim 2001

[43] Dzidowski E.S., Problems of numerical modeling of processes determined by shear fracture, In: Materials processing and design. Modeling, simulation and applications, Proceedings of the 9th International Conference on numerical Methods in Industrial Forming Processes, NUMIFORM 2007 (June 17-21, 2007 Porto Portugal) American Institute of Physics, 2007,1615-1620
[44] Dzidowski E.S., Shear fracture mesomechanics: new modelling strategies and criteria, In: Sih G. C. and de Castro M. S. T.( Eds.), Multiscale behaviour of materials and structures: analytical, numerical and experimental simulation, Proceedings of the VIII International Conference of Mesomechanics (July 1922, 2006 Porto Portugal), Porto Publindustria, 2006, 83- 90

[45] Dzidowski E.S., Physical mesomechanics as a missing link needed to understand, model and control of main aspects of plasticity and fracture of ductile materials, In: Sih G. S. and Vu-Khanh T. (Eds.) Materials for safety and health. Mesoscopic and multiscale consideration in modern science and engineering (August 1-4, 2005 Montreal Canada), Ecole de Technologie Superieure, 2005, 312-319

[46] Dzidowski E.S., Some critical remarks about application of known fracture criteria in modelling processes determined by shear fracture, In: Stoeren S. (Ed.) the 7th Esaform Conference on material Forming. ESAFORM 2004 (April 28-30, 2004 Trondheim Norway) Proceedings of Norwegian University of Science and Technology, 2004, 745-748

[47] Dzidowski E.S., Chruscielski G., Mesoscopicmacroscopic model of chip formation during machining $i$ quasi-isothermal conditions, In: Brucato V. (Ed.) Proceedings of the 6th ESAFORM Conference on Material Forming (April 28-30, 2003 Salerno Italy), Nuova Ipsa Editore, 2003, 523-526

[48] Dzidowski E.S., Advancements of fracture mesomechanics in sheet metal forming processes, In: Habraken M. (Ed.) Proceedings of the 6th ESAFORM Conference on Material Forming (April 23-25, 2001 Liege Belgium), Derouaux Ordina, 2001, 241-244

[49] Dzidowski E.S., Sheet limit-strain-curve concept based on structural aspects of nucleation and development of strain localization on shear bands, In: Fritz H. G. (Ed.) 3rd ESAFORM Conference on Material Forming (April 11-14, 2000 Stuttgart Germany), Institute fuer Kunstofftechnologie Universitaet Stuttgart, 2000

[50] Dzidowski E. S., Shear fracture at liquid nitrogen temperature, Materials Science and Engineering, A Structural Materials: Properties, Microstructure and Processing, 1993, 168, 11-16

[51] Dzidowski E.S., The mechanism of shear fracture in the aspect of micro- and macrolocalization of strains, In: Teodosiu C. and Sidoroff R. F. (Eds.) Fundamental aspects and applications to metal forming, Proceedings of the International Seminar MACAMAT'91 (August 7-9, 1991 Fontainebleau France), A. A. Balkema, 1993, 213-218 
[52] Dzidowski E.S., The genesis of s-like fracture shape during transverse shearing of metals, In: Anisotropy and localization of plastic deformation, Proceedings of Plasticity'91: The Third International Symposium on Plasticity and Its Current Applications (August 1216, 1991 Grenoble France), Elsevier,1991, 67-74

[53] Dzidowski E.S., The mechanism of ductile fracture during transverse shearing, In: Lange K. (Ed.) Advanced Technology of Plasticity 1987 (August 2428, 1987 Stuttgart Germany), Springer Verlag, 1987, 283-290

[54] Dzidowski E.S., A study of limiting displacements in the shearing of bars, Journal of Mechanical Working Technology, 1986, 12, 297-306

[55] Dzidowski E.S., The occurrence of localized shear bands during transverse shearing, In: COBEM'85,
Annalis do VII Congresso Brasileiro de Engenharia Macanical (Dezembro 10-13, 1985 Sao Jose dos Campos), 907-910

[56] Dzidowski E.S., The effect of strain hardening factor on limiting displacements during transverse shearing, In: Conference proceedings of 1st ICTP advanced technology of plasticity 1984 (September 3-7, 1984 Tokyo Japan), 617-622

[57] Mishnaevsky L.L. Jr, Methods of the theory of complex systems in modelling of fracture: A brief review, Engineering Fracture Mechanics, 1997, 56, 47-56

[58] Panin V.E., Physical fundamentals of mesomechanics of plastic deformation and fracture of solids, Acta Metallurgica Sinica, 1997, 33, 187-197 